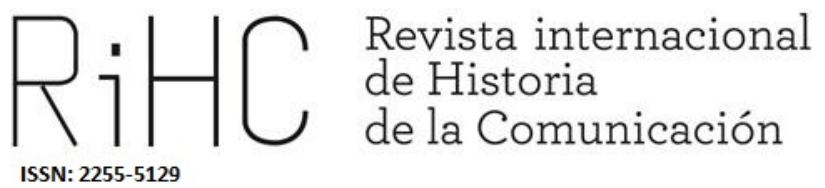

\title{
DEL PELO CORTO A LA \\ CABELLERA DESPEINADA: \\ GENEALOGÍA DE LOS CUERPOS \\ JUVENILES EN LAS REVISTAS \\ ILUSTRADAS CHILENAS ${ }^{1}$
}

From short hair to disheveled hair: genealogy of juvenile bodies in Chilean illustrated magazines

DOI: http://dx.doi.org/10.12795/RiHC.2018.i10.04

Recibido: 28/03/2018

Aceptado: $18 / 05 / 2018$

Publicado: $25 / 05 / 2018$

Marcela Eliana Saa Espinoza (iD) https://orcid.org/0000-0002-6895-0892

Universidad Autonóma de Barcelona, marcelasaae@gmail.com

Resumen: Los jóvenes chilenos fueron tempranos productores y consumidores de revistas ilustradas, y desde principios del siglo XX utilizaron imágenes para representarse visualmente. En ese escenario, el cuerpo retratado de la juventud fue central a lo largo

\footnotetext{
${ }^{1}$ Este artículo se enmarca en los resultados de investigación del Proyecto Fondecyt N¹161126/Chile, y en el desarrollo de la investigación doctoral de la autora en el programa de Antropología Social y Cultural de la Universidad Autonóma de Barcelona.
} 
del siglo XX para la construcción de discursos acerca de lo correcto, normal y hegemónico sobre esta identidad. Este artículo analiza específicamente dicha corporalidad y visualidad a lo largo del siglo, a través de las transformaciones de la cabellera juvenil, como un fragmento corporal que, en tanto signo, se transformó en un medio de diferenciación generacional a través de puestas en escenas marcadas por la moda global y local. Se busca trazar una genealogía de lo juvenil y la metodología utilizada para analizar es la de Atlas de Imágenes, siguiendo las ideas de Aby Warburg (2010), donde se describen y relacionan imágenes fotográficas de diferentes peinados y cortes a la moda a lo largo de revistas de todo el siglo XX, junto a imágenes icónicas de las cabelleras juveniles latinoamericanas.

Palabras clave: Jóvenes, genealogía, imágenes, atlas, cabellera

\begin{abstract}
Young Chileans were early producers and consumers of illustrated magazines, and since the early twentieth century they used images to represent themselves visually. In this scenario, the portrayed body of youth was central throughout the twentieth century for the construction of discourses about what is correct, normal and hegemonic for this identity. This article specifically analyzes this corporality and visuality throughout the century, through the transformations of the juvenile hair, as a body fragment that, as a sign, became a means of generational differentiation through stagings marked by global and local fashion. The aim is to trace a genealogy of the juvenile and the methodology used to analyze is that of Atlas of Imagenes, following the ideas of Aby Warburg (2010), where photographic images of different hairstyles and fashionable haircuts are described along with magazines throughout the 20th century, together with iconic images of the Latin American juvenile hair.
\end{abstract}

Keywords: Young, genealogy, images, atlas, hair

\title{
1 Introducción
}

Los jóvenes, como sujetos modernos, son una construcción histórica y cultural. Los atributos, estéticas y lugares donde los ubicamos han ido modificándose según múltiples discursos culturales que han moldeado dicha subjetividad. Este artículo indaga en los modos de construcción del cuerpo juvenil a partir de un enfoque genealógico. Una advertencia es necesaria: no realizaremos una historia de la cabellera juvenil, ni pretendemos contextualizar épocas y peinados de moda, sino por el contrario, avanzar en una genealogía que, como señalara Foucault ([1971], 2008), permita visibilizar "los mecanismos de producción de verdad", que permitieron la construcción de una idea de juventud.

La puerta de entrada a este artículo es un fragmento del cuerpo joven: la cabellera. Ésta funciona como un signo-indicio que, como una señal de algo más, nos permite comprender cuáles fueron las formas de habitar y construir este cuerpo. El cuerpo, siguiendo a Foucault ([1971], 2008), está impregnado de múltiples discursos y saberes 
que disputan el poder, y consideramos que la cabellera forma también parte de ello. En este escenario, la moda emerge como uno de los discursos que buscará fijar ciertos modos de llevar este cabello, y estará vinculada no sólo con los modelos provenientes de la industria mediática nacional sino, como veremos, con modas globales y procedentes de múltiples espacios discursivos.

Las imágenes de las cabelleras juveniles circularon en un espacio privilegiado y al mismo tiempo delimitado de observación y consumo: las revistas juveniles. En Chile, estos medios se produjeron tempranamente y en las primeras décadas existían variados magazines para estos sujetos. Así, analizaremos múltiples imágenes provenientes de las revistas durante el Siglo XX, específicamente entre los años 1905 y $1989^{2}$-. El análisis que aquí proponemos está basado en analizar imágenes a partir de montajes de distintas piezas visuales que conforman paneles -siguiendo las ideas de Atlas de imágenes del historiador Aby Warburg (2010).

\section{Estado de la cuestión}

\subsection{Jóvenes y genealogía}

Una primera consideración es necesaria respecto al análisis propuesto que aquí conceptualizamos como genealogía, y que remite a una forma específica de problematización y tratamiento de materiales y documentos históricos. La genealogía, como perspectiva teórica-metodológica, ha sido propuesta por Michel Foucault ([1971], 2008) y a partir de ella es que planteamos nuestro interés en visibilizar los mecanismos de producción de verdad que permitieron la construcción de una idea de juventud y específicamente relevar aquellos discursos y estrategias materiales que acompañaron la construcción del cuerpo juvenil.

¿Y por qué la juventud? Podemos señalar que, desde las ciencias sociales y humanas, la juventud es entendida como una categoría que se ha construido social y culturalmente, variable según el tiempo y lugar de enunciación. Desde el Siglo XX veremos el nacimiento, desarrollo y consolidación de este sujeto con prácticas específicas y segregadas frente a otros grupos de edad (Feixa 1998, 2004). En tanto categoría de lo

\footnotetext{
${ }^{2}$ La elección temporal responde al marco histórico en que la investigación Fondecyt está centrada: en medio de dos hitos centrales para la industria de la comunicación, 1905 y la creación de los primeros boletines juveniles chilenos y 1973, con el inicio de la dictadura cívico militar que modificó radicalmente los modos en que dicha industria funcionaba a partir de la quiebra de editoriales, censura de medios y creación de revistas estatales.
} 
social, la juventud se ha estudiado históricamente (Pérez Islas \& Urteaga 2004, Aguilera 2014, Toro 2012) y será desde la antropología de las edades que se deconstruirá su universalidad haciendo evidente con ello los modelos de sociedad que permiten determinadas juventudes, y también reconociendo las diversas prácticas de poder que constituyen su especificad, desde la clase, el género y la raza, entre otros.

En un artículo anterior (Saa, 2016) argumento que, si bien el estudio culturalista de la juventud ha sido fundamental en la construcción de una historia de los jóvenes -en particular en el estudio de las culturas juveniles-, es necesario avanzar en una genealogía de lo juvenil para dar cuenta de las formas de producir dicha construcción enfatizando en las prácticas discursivas y los efectos de verdad resultantes, conectando con ello los procesos y sucesos que posibilitan la existencia de esta categoría de estudio.

Otra dimensión relevante desde una perspectiva de construcción cultural de la juventud es la identificación y atención con/sobre el cuerpo joven, en la medida en que "el cuerpo es el vehículo primero de la socialidad. De su conquista y domesticación depende en buena medida el éxito o el fracaso de un proyecto social" (Reguillo, 2012:59). El cuerpo amplía el foco analítico sobre el sujeto juvenil, en tanto expresa de forma condensada las disputas por la identidad que se encuentran producidas/atravesadas por relaciones de poder y asimetrías (Nateras, Valenzuela y Reguillo, 2007).

La genealogía como perspectiva reconoce por su parte la centralidad del cuerpo como el lugar donde los acontecimientos impactan y se articulan, o se desmoronan y se ponen en crisis. Como sostiene Foucault: "la genealogía, como análisis de la procedencia, está, pues, en la articulación del cuerpo y la historia. Debe mostrar el cuerpo totalmente impregnado de historia, y la historia arruinando el cuerpo" (2008: 32). Por ello, la preocupación por el cuerpo es fundamental tanto teórica como metodológicamente.

A partir del modelo genealógico para estudiar la juventud, buscamos evidenciar la construcción de una idea de juventud, que no es otra cosa que una idea sobre su cuerpo y representación, indagando a través de determinados tipos de discursos y estrategias materiales que acompañaron la confección de dicha idea durante el siglo XX. Esta estrategia nos permite observar la materialización de la cultura, ya que la relación de la materialidad del cuerpo con la discursividad de los saberes de distintas instituciones que lo constituyen, permite objetivar las diferencias y producir subjetividades (Butler, 2002). Es así como uno de los discursos que acompañaron buena parte del Siglo XX a la juventud, es aquel vinculado al campo del consumo y la industria cultural, que en tanto espacios de lo social devinieron referentes (y hegemónicos) para la propia existencia social de este grupo. ${ }^{3}$

\footnotetext{
${ }^{3}$ El ejercicio genealógico me ha llevado a indagar en una serie de discursos que acompañaron la construcción de la idea juvenil. Si bien en este artículo se presentan los discursos vinculados a la industria cultural, el teenage market y la moda, reconocemos los discursos higienistas, legislativos, educativos,
} 
A partir de lo anterior es que sostengo que, en los discursos provenientes de la moda, el cine, la música, el mercado los magazines, y la cultura de masas, existen elementos y datos que dan cuenta sobre aquellos procesos que se necesitaron para que durante distintos momentos del siglo XX se consolidaran ideas en torno al cuerpo joven que lo hacían legitimarse, diferenciarse y normalizarse frente a otros. De allí que no se trata de elaborar una historia de la juventud durante el siglo XX, sino de ubicar/reconstruir las condiciones de posibilidad de los discursos sobre el cuerpo juvenil: rastrear las articulaciones que permitieron la producción de un cuerpo juvenil, reconstruir las significaciones resultantes que visibilizaban a esta juventud, y establecer las conexiones entre el ámbito de las ideas y de lo material en relación a este sujeto.

\subsection{Jóvenes y medios}

Desde mediados del Siglo XIX en Chile se comenzaron a vivir una serie de transformaciones en los ámbitos políticos, económicos, sociales y culturales ligados a la modernidad. Los cambios a nivel mundial respecto a la modernización, revoluciones industriales, políticas y sociales, cambiaron la forma de comprender el mundo y en Chile la recepción de aquello influyó en la transformación de los modos de producción, circulación y recepción de los nuevos discursos de y sobre la sociedad.

En Chile se observa, desde mediados del Siglo XIX, una amplia proliferación de múltiples medios de comunicación, escritos, visuales y sonoros, que rápidamente se expandieron desde la capital a diversos centros urbanos del norte y sur del país (Rinke, 2002). Fue a partir de esta época que en Chile se evidencia una etapa de modernización, visible tanto en la producción industrial a gran escala como en una variada producción de medios de entretenimiento y comunicación que se consolidarían durante las primeras décadas del Siglo $X X$, y que se transformarían en un vehículo privilegiado desde donde se fue desplegando la discursividad moderna.

La diversicación de los medios de comunicación escritos se aprecia con mayor intensidad en la primera década del Siglo XX. La creación de la editorial Zig-Zag y el desarrollo de sus revistas, marcarán un hito en esta materia (Ossandón y Santa Cruz, 2001). Las revistas ilustradas como Almanaque y Sucesos (Editorial Universo), llegaban a un público heterogéneo y tuvieron una circulación de más de tres mil ejemplares en la primera década del Siglo XX. Entre sus características se apreciaba el uso de caricaturas, gran impresión de imágenes y la escritura sobre los más diversos tópicos de actualidad

En cuanto a las revistas juveniles, estos corresponden a un sinfín de medios de comunicación que cumplieron un papel activo durante el Siglo XX en la producción y

cívicos y publicitarios, como otras narrativas que constituyeron ideas e imágenes sobre juventud. Ver más en Saa, 2015, 2016. 
circulación de información, noticias, eventos e imágenes hechas por y para los jóvenes (Aguilera, 2014). La amplia producción de revistas y medios escritos juveniles se enmarca por lo tanto, en el momento del despliegue de los medios de comunicación chilenos en general, el cual tuvo al siglo XX como escenario político y cultural principal para su desarrollo (Santa Cruz, 2014).

Cabe señalar, que las revistas para la juventud, son concebidas de forma casi unánime como aquellas producidas bajo la lógica del tennage market de la posguerra, donde la coyuntura social, política y cultural produjo una emergencia de los jóvenes, con visibilidad y consumo a escala global. Y es que las revistas para jóvenes como tal, y que son las que conocemos en la actualidad tipo "seventeen", no están presentes por Zig zag sino aproximadamente hasta los años 1960, momento en que se empieza a ofrecer productos más específicos que engloban múltiples intereses juveniles. Para el caso chileno, será la revista Ritmo la que se ha consagrado en el imaginario como la que inaugura este tipo de productos, y es la más importante revista de jóvenes durante el siglo (Lamadrid, 2014).

A pesar de lo dicho anteriormente, fue la revisión del archivo, donde pudimos observar que, desde inicios del Siglo XX, los jóvenes tuvieron medios de comunicación propios, y que, si bien fueron muchas veces pequeños boletines, o revistas con muy corta circulación, tuvieron un espacio en la escena comunicacional nacional y además utilizaron fotografías con gran entusiasmo.

Como señala Aguilera (2014), se ha invisibilizado toda la producción de magazines juveniles previos a la década del 60 , así como otras adscripciones que produjeron estos medios, tal como los partidos políticos o la escuela, entre otros. Esto se ha dado principalmente, a juicio del autor, porque se ha tomado el periodo de posguerra como momento inaugural de la juventud y sus consumos culturales, no visibilizando otros regímenes de juvenilidad anteriores, que además produjeron revistas dedicadas a la participación política y a la prosa literaria, por ejemplo, o revistas femeninas y juveniles que a través de publicidades y reportajes enseñaban a las jóvenes a comportarse y cultivar sus cuerpos, produciendo una verdadera pedagogía del cuerpo juvenil (Aguilera \& Saa, 2016). De esta forma sostengo que, la noción actual que tenemos sobre los medios de comunicación juvenil -aquellos con énfasis en la música o moda en exclusiva, no fueron hegemónicos sino hasta finales de la década de 1960, por lo que estamos frente a medios que propondrán una diversidad de elementos culturales constitutivos de "modas juveniles", y que irán desde la poesía hasta la política y la militancia.

Otra característica importante de estos medios fue el uso que hicieron de las imágenes, las que tuvieron funciones similares que en los medios de comunicación en general: ilustrar y documentar acciones, presentar y resaltar actores, y mostrar nuevos o importantes espacios públicos y privados. La fotografía y los dibujos, se utilizaron en los distintos medios en distintas funciones comunicativas, como ser imagen de portada y 
contraportada, de ilustración en los distintos reportajes y crónicas, así como también en la publicidad y láminas promocionales al interior de las revistas. De esta forma, podemos decir que las imágenes acompañaron a partir de diferentes funciones, los lenguajes e intereses juveniles

Por último, debemos señalar en torno al campo de las revistas, que las consideramos como unidades de sentido que no están cerradas sobre sí mismas, ni dependen sólo de la ideología de su editorial. Por el contrario, las comprendemos como espacios abiertos que se construyen a partir de múltiples discursos, imágenes y textos, y que no sólo reproducen ideas preconcebidas sobre la sociedad, sino que proponen modelos de sociedad que, conforme al tiempo, se irán legitimando o no.

\subsection{Jóvenes y moda}

Las revistas juveniles tuvieron como principal atractivo posicionar, desde distintos espacios editoriales, los intereses para este grupo y presentarlos a través de artículos, noticias, textos en general, pero sobre todo a partir de imágenes visuales. Desde la primera década del Siglo XX en adelante, los más diversos medios juveniles hicieron uso de imágenes fotográficas, dibujos, collages y una serie de visualidades para acompañar sus publicaciones. En dichas imágenes se reflejaban los tópicos de interés juvenil, que iban desde visualidades de naturaleza y aire libre, hasta los retratos posados de las reinas de la primavera durante las primeras décadas. Posteriormente, desde imágenes de las modas y vestimentas en París durante los años 30 , hasta las estéticas de las guerrillas en los 60, y los bailes televisivos en los 70. Desde ese punto de vista, podemos señalar que existe una diversidad de "modas juveniles" circulando a través de estas plataformas mediales.

Cabe señalar que el campo de los estudios sobre la moda incluye una serie de fenómenos, tales como la industria de la moda a nivel internacional, el sistema de estrellas vinculados a dicha empresa, el consumo de masas, como también el análisis histórico a la indumentaria, y los discursos que promueve la moda y los respectivos impactos en determinados públicos. Es así como en la década de los 70, la moda se transformaría en una dimensión de análisis social. Siguiendo a René König es posible reconocer tempranamente la necesidad de desanclar la noción de moda a la cuestión puramente indumentaria, y más bien, comprender a la moda como un sistema de arreglos que regula la corporalidad humana. Para esta investigación entenderemos el concepto de moda en un sentido amplio, donde se reconocen prácticas e intereses variados que se transformaron en tendencia y hegemonía del consumo juvenil según una serie de condicionantes y vehículos movilizadores de dichas estéticas. La moda se constituye en un discurso que moviliza ideas, deseos y regulaciones, y genera determinados efectos en el cuerpo social: 
Dado que constituye una institución social general, la moda abarca y configura al ser humano por entero. Por consiguiente, también resultan insuficientes aquellas representaciones de la moda que la conciben simplemente como el arte de la indumentaria o la historia del traje. En realidad, la moda constituye un principio de configuración cultural universal que no sólo puede abarcar y configurar el cuerpo del hombre en su conjunto, sino también sus medios de expresión." (König, 1972:20)

König señala que la moda en tanto sistema social es una fuente creadora de cultura a la vez, por lo que, desde ese punto de vista, coincide con nuestro enfoque de considerar la moda como discurso que es capaz de movilizar ideas y generar efectos en la sociedad.

¿Y cuáles fueron los discursos de moda que impactaron la configuración de la juventud chilena? ¿Cómo se representaron en los medios de comunicación? Creemos que las imágenes visuales se constituyen como espacio privilegiado para analizar y responder estas preguntas. Desde ellas es posible analizar las representaciones de las modas, así como los vínculos con otros discursos e imágenes. Sostenemos que las imágenes en los medios, siguiendo a Castro Gómez (2009), contribuyeron a producir y movilizar deseos, delineando así la nueva sociedad moderna que estaba construyéndose. Analizarlas no sólo nos permite comprender la moda, sino todo aquello a su alrededor que permitía el legítimo ejercicio de esta en la sociedad chilena.

De todas las imágenes y referentes que surgen en las revistas juveniles, será una representación específica de la que nos haremos cargo en este artículo: las cabelleras. El rostro y la cabellera desde el análisis social siempre han indicado ser metáfora y símbolo de ciertos rituales sociales. Dicho fragmento corporal ha sido históricamente un elemento relevante en la construcción del cuerpo, así como de su diferenciación de género, clase y generación, y variable según modas y estilos locales y globales. La importancia de esta zona corporal ha sido central también en las representaciones iconográficas de la pintura y la fotografía a través del retrato (Tagg, 1998) así como en los múltiples estudios etnográficos (Leach, 1958; Hallpike, 1969; Hershman, 1974).

De esta manera, podemos señalar que la cabellera y sus transformaciones no es una temática de interés puramente actual, ni concerniente de forma particular a la industria de la moda y la estética, sino que ha sido una marca corporal de importancia universal que puede verse en las esculturas de Venus de Willendorf y Venus de Brassempouy, o en las cabelleras rapadas femeninas y el uso de pelucas en Egipto como signos de distinción (Loy y Vidart, 2008).

A partir de lo anterior, propongo estudiar este fragmento corporal en tanto signo indiciario. Esto quiere decir que la cabellera funciona como una marca especifica de juvenilidad que varía según tiempos, estéticas y modas particulares, y que rastreando sus estabilidades y rupturas nos revela ciertos modos en la configuración del cuerpo joven que se diferencia de otros cuerpos como los adultos o infantiles. Así, la cabellera 
nos permite acceder al conjunto de arreglos sociales, institucionales, interacciónales que la hacen posible.

\section{Metodología}

Esta investigación es de carácter cualitativo y documental. La utilización de documentos y su relevancia está ampliamente consignada en las ciencias sociales (Mills, 1961; Valles, 1999). No obstante, el método documental y sus fuentes de base han sido hegemónicamente textuales. En nuestro caso, proponemos que los documentos sean preferentemente visuales, en tanto "las imágenes son una forma importante de documento histórico. Reflejan un testimonio ocular" (Burke, 2001: 17).

\subsection{Muestra}

El universo de selección de los documentos visuales tiene dos fuentes. La primera son las revistas o medios juveniles chilenos que circularon durante el siglo XX (1905-1973), con 84 medios de comunicación juveniles producidos por y para jóvenes desde distintas editoriales y adscripciones mediáticas (políticas, religiosas, asociativas y provenientes de la industria cultural). La segunda fuente es la base de datos de imágenes de google, desde donde se pudo buscar y descargar imágenes visuales que ayudaron a contextualizar la muestra principal que trabajamos, en otras palabras, son imágenes que se relacionan temáticamente con las imágenes provenientes de los medios juveniles, y que funcionan como elementos transculturales que ayudan a completar los sentidos de las imágenes, a pesar de la diversidad de soportes donde circulan, así como el tiempo de su producción. Finalmente se trabajó con 34 imágenes, 29 provenientes del archivo de revistas juveniles construidas, y 5 de google.

El trabajo de selección de las imágenes visuales consistió en un ejercicio de revisión de archivo, donde se eligieron imágenes que representaran con mayor fuerza la temática de la cabellera. Eso se realizó según los postulados de Roland Barthes (1989), a través de su noción de stadium y punctum, que señalan que en las imágenes es posible identificar al realizar el análisis preliminar - la observación-, al menos dos cuestiones: a) la identificación "universal" de la temática representada en la imagen, lo que permite indicar en este caso si se trata o no de imágenes que representan el cabello (stadium), $y, b)$ el reconocimiento por parte del investigador, de algún elemento sobresaliente de la imagen y que llama su atención de forma subjetiva, "un detalle que conmueve", y que en este caso se tratará de imágenes que como investigadora se consideren necesarias para dar cuenta de los objetivos de esta investigación. 


\subsection{Estrategia analítica}

Las operaciones metodológicas para el trabajo con documentos visuales consistieron en organizar dichas fuentes a partir de la creación de un atlas de imágenes (Warburg, 2010), para lo cual fue necesario realizar agrupaciones de imágenes (paneles) que permitiesen identificar los núcleos de análisis específicos a desarrollar (ver imagen 1).

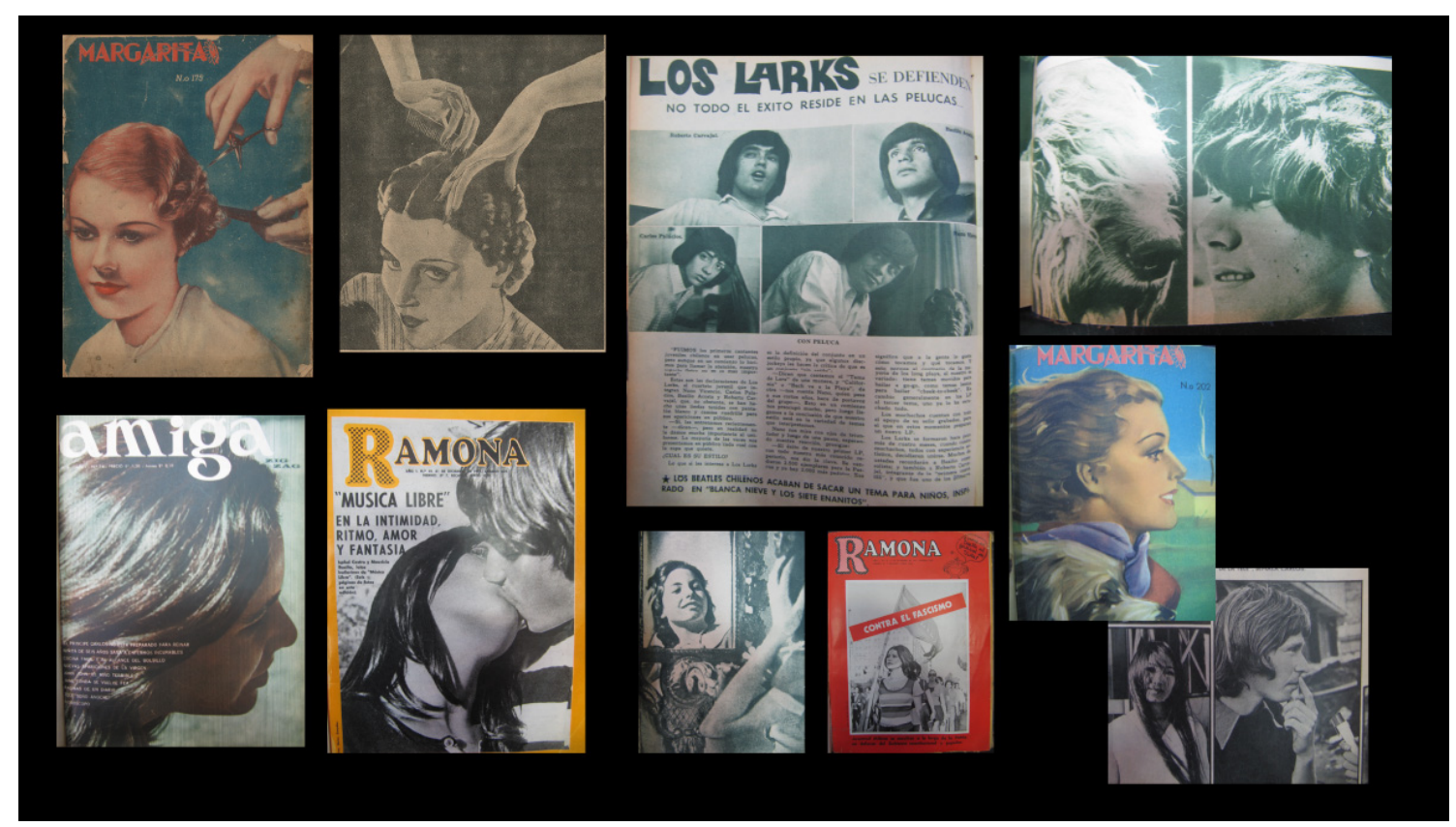

Imagen 1: Panel cabelleras revistas juveniles.

Los paneles, inspirándonos en Warburg, organizarán conjuntos de imágenes según su afinidad temática. En otras palabras, se trata de una agrupación de imágenes sin mayor jerarquía técnica ni temporal entre ellas, que estarán unidas por un sentido de afinidad. Esta correlación, siguiendo un proceso de montaje (Huberman, 2010), está dada principalmente por quien investiga, otorgando una multiplicidad de imágenes para crear paneles densos para el análisis, y que se correspondan con los objetivos de investigación propuestos,

La propuesta del Atlas Mnemosyne de Warburg es compleja e inacabada, por lo tanto, abierta a la innovación y la experimentación visual, que nos invita a utilizar las imágenes visuales como fuentes primordiales, defendiendo su estatuto específico frente al texto escrito, y abriendo el análisis no sólo a sus contenidos, sino también a los motivos o contextos de producción. Las imágenes dialogan así junto a otras imágenes, y el montaje que produce cada panel trae de vuelta una memoria de las imágenes, de cómo sus recurrencias aparecen una y otra vez en la cultura visual. Si para Warburg fueron los gestos, el movimiento y ciertas emociones, los modos de entender la cultura -la 
memoria de las imágenes-, éstas se presentarán para nosotros como nudos analíticos a los cuales acercarse para investigar las imágenes del cuerpo joven.

Para este artículo organizamos cuatro paneles, cada uno de ellos es una unidad de sentido singular, y un montaje de heterogéneas imágenes, que permiten comprender las múltiples formas de habitar y construir el cuerpo juvenil, y que desde la cabellera se podemos acceder.

\section{Resultados}

En palabras de Warburg, las imágenes sobreviven y sus motivos traspasan fronteras temporales para representar ciertos motivos del cuerpo. Si bien la memoria de las imágenes y el modelamiento del cuerpo está presente en una multiplicidad de imágenes, y todas ellas ayudan a constituir los modos culturales de entender y aprehender sus significados, a continuación, observaremos cuatro paneles construidos en base a imágenes visuales de distintos tiempos que circularon en Chile y medios de comunicación juveniles principalmente.

\subsection{Panel 1: Cabello corto y fijo}

La moda del cabello corto para las mujeres, así como un estilo fijo y quieto no ha sido patrimonio exclusivo de las mujeres modernas de los años 20 , ni tampoco de las de los 60. Esta característica, como podemos observar en este primer panel (Imagen 2), nos habla de las formas en que esta moda tuvo presencia en distintos momentos del Siglo $X X$, y no sólo se vinculó a estéticas juveniles específicas, sino que también a controles corporales particulares que fijaron dichas cabelleras. 


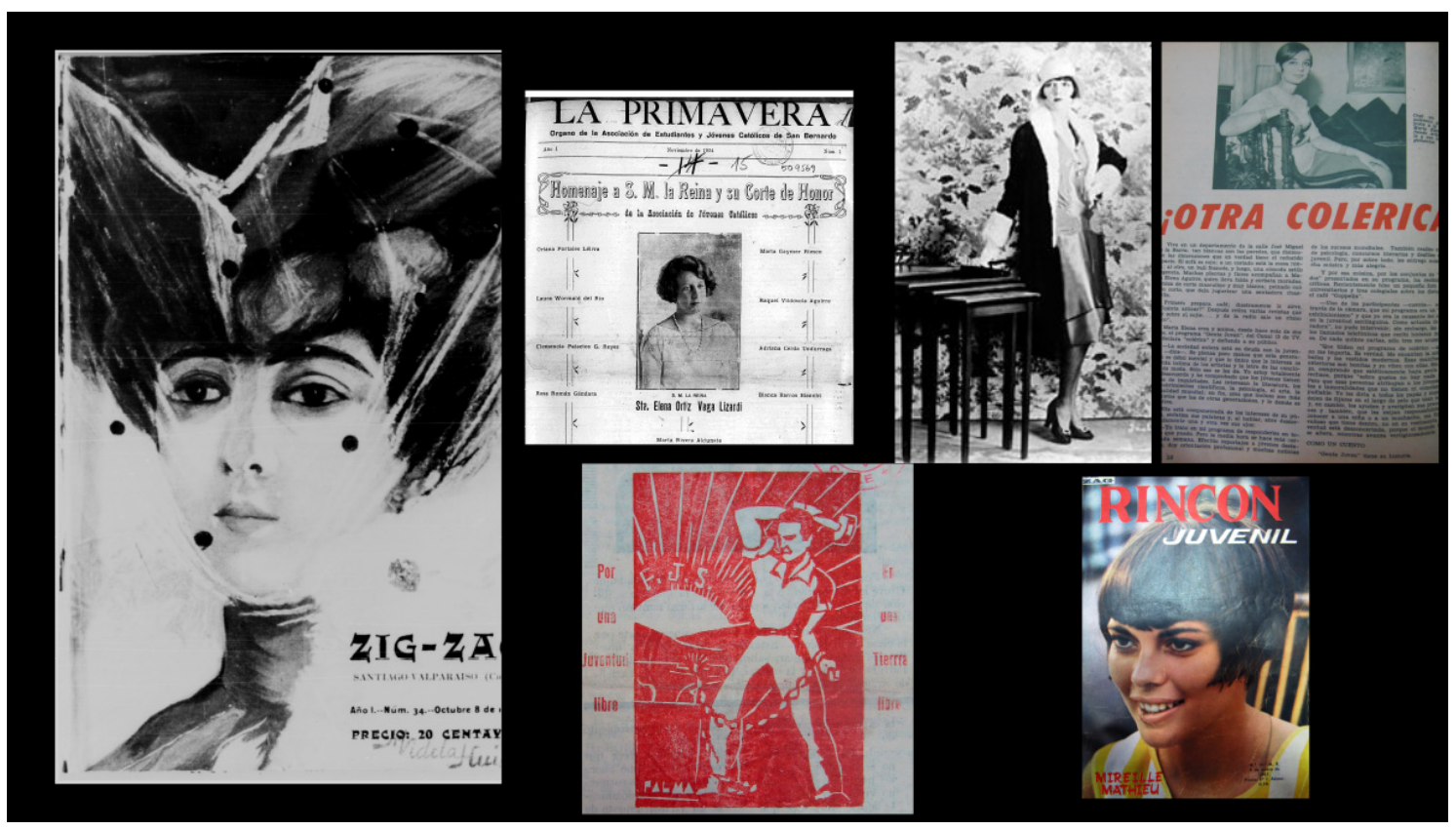

Imagen 2: Panel 1 Cabello Corto y Fijo.

Las mantas para el cabello -también conocidos como tocados-, fueron un accesorio que ayudó a fijar los cabellos de las mujeres, muy en boga a principios del siglo XX, y que tendrá un momento de gran visibilidad con la Belle Epóque. Sin bien los sombreros aparecieron en muchas imágenes de las jóvenes, también observaremos que se utilizaron los pañuelos para fijar y tapar el cabello, haciéndolo rígido como observamos en la imagen de 1905 de la revista Zigzag (En panel 1, fotografía izquierda).

Posteriormente la estética flapper tendrá una importante aparición en la sociedad chilena, cuando a mediados de los años 20, como señalan Rinke (2002) y Vicuña (2001), irrumpieron en la clase alta chilena jóvenes que seguían los patrones norteamericanos estéticos invocando una nueva juventud. Si bien para el caso chileno las mujeres jóvenes no fueron tan contestarías como en el mundo estadounidense, la estética sí irrumpió con fuerza y las jóvenes con sus cabelleras cortas y la nuca descubierta salieron a bailar, al cine y otros espacios de ocio que años atrás estaban diseñados exclusivamente para varones.

El cabello corto de la flapper, melena lisa y con una chasquilla en la frente, muchas veces oscuro y brillante, apareció en las imágenes de las revistas juveniles, pero no con la fuerza que tuvo la cabellera rubia y ondulada. Las flapper, si bien serían durante un par de años mujeres jóvenes que marcarían tendencia y harían de su imagen la hegemonía de la joven moderna, no tuvieron la constancia de la rubiedad (ver panel 2).

Estas cabelleras femeninas y fijas estuvieron presentes en buena parte de las imágenes de los años 20 y 30 en revistas asociativas y estudiantiles, donde se pueden observar fotografías de jóvenes chilenas en contextos de presentación en sociedad o premiaciones. Se trata de imágenes locales, fundamentalmente. Esto cambiará con la 
introducción sistemática de revistas juveniles provenientes de la industria cultural, donde otros modelos de corporalidad y estética disputarán visibilidad y que tendrán su origen en imágenes provenientes del arte, el cine extranjero, así como fotografías de archivos internacionales, etc.

Para el caso de la imagen vinculada a la flapper, ésta tuvo un salto durante el siglo y reapareció en el contexto chileno en la década de los 60, acompañando a la figura de "las y los coléricos", que como señala Yanko González (2011), serían unas de las primeras culturas juveniles en el país. Los coléricos movilizaron estéticas, consumos culturales música principalmente-, y dotaron de importancia a la cabellera. Así, el pelo juvenil volverá a fijarse corto casi como invocando aquellas ideas de modernidad e independencia de los años 20 , y que resurgen a través de la estética femenina colérica.

El pelo corto y fijo tendrá estos dos momentos de mayor visibilidad durante el siglo XX, y cada uno de ellos tendrá en el cuerpo femenino y la estética de este peinado, una forma semi contestaría de presentarse en sociedad.

Las cabelleras fijas también estarán presentes en la representación de los hombres durante buena parte de la representación iconográfica de las revistas y boletines. Como podemos mirar en el grabado del boletín presente en el primer panel (imagen centro), la representación imaginada del hombre joven, trabajador en este caso, produce una visualidad con énfasis en un cabello corto y sin movimiento.

Para el caso masculino, la representación de su cabello corto irá cambiando en forma sustancial y progresiva a lo largo del siglo, donde distintas estéticas, así como su extensión, devienen modos de rebelión y contestación frente a los adultos (ver panel 4). Es importante recalcar aquí que dichas influencias provenientes de estilos y modas globales afectaron en Chile principalmente en jóvenes de clases acomodadas no influyendo en las capas medias ni populares como sostiene González (2011), y como lo veremos en imágenes, los retratos de estos jóvenes coinciden con jóvenes de las clases medias altas que consumen y portan las nuevas modas norteamericanas provenientes del teenage market.

\subsection{Panel 2: Rubiedad y movimiento}

La cabellera rubia asociada a los cuerpos exuberantes, bellos y jóvenes, ha sido un patrón constante en las imágenes de la industria cultural, como ideal representacional del cuerpo joven y deseable. En América Latina, dichas ideas de rubiedad se popularizaron tempranamente a partir de las modas europeas, pero principalmente con la llegada del sistema de estrella hollywoodense que proponía modelos rubios como los cuerpos ideales, exitosos y famosos en la sociedad. Este segundo panel (Imagen 3), muestra los principales íconos rubios y juveniles, y ciertas imágenes que aparecieron 
para sedimentar en otros lenguajes la hegemonía de estos rasgos fenotípicos en la construcción de un cuerpo joven.

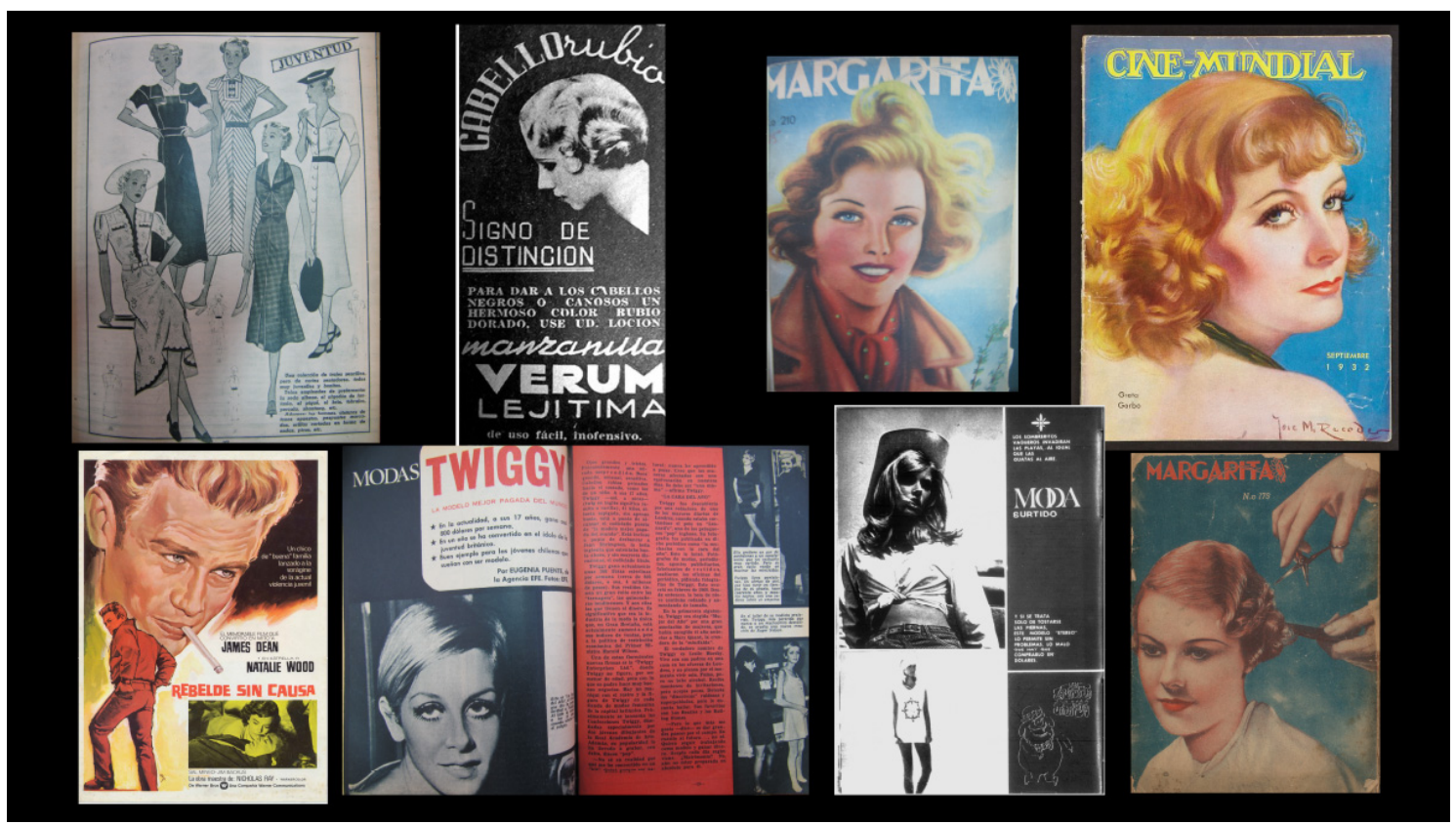

Imagen 3: Panel 2 Rubiedad y Movimiento

Durante la década de los 30 una mujer se volvió central para los chilenos: Greta Garbo. Como distintos autores han señalado (Purcell 2012, Rinke 2014), el cine norteamericano ingresó con gran fuerza al país después de la I Guerra Mundial, y como estrategia de comercialización introdujo la presencia de la imagen del ídolo. El cine hollywoodense requirió una diversidad de dispositivos para masificarse, entre los que contamos los medios de comunicación escritos, revistas especializadas en cine, así como revistas magazinescas de todo tipo (Santa Cruz, 2014).

Las fotografías de glamour como se les conocerán a los retratos de estrellas provenientes del cine -y Hollywood para el caso chileno, principalmente-, y que se utilizaban en portadas y publicidades de las revistas, se desarrollaron en las décadas de 1920 y 1940 y tuvieron como características potenciar determinados atributos de estos ídolos. Fue así que las revistas no sólo contribuyeron a la masificación y comercialización del cine, sino a sedimentar ciertas ideas en torno a la corporalidad que se fueron convirtiendo en aspectos de gran deseabilidad por parte de las chilenas y chilenos.

Una de las imágenes más difundidas, fue aquella que realzaba a las estrellas con una cabellera rubia, exuberante, con volumen -y buena parte del tiempo en movimiento-. Ya bien sus rostros expresaran cólera o felicidad, este montón de cabellos rubios constituían lo central de la imagen. Cabe señalar que estas imágenes de estrellas tenían un correlato local en las revistas juveniles de la época, que reproducían imágenes de 
todo tipo invocando este modelo corporal. Margarita (1934-1959), por ejemplo, fue una revista femenina y juvenil chilena que utilizó múltiples portadas con imágenes de jóvenes anónimas, o dibujos/copias de fotografías de mujeres jóvenes rubias. En este panel pudimos observar este tipo de imágenes, así como publicidades y secciones de este magazine, donde la cabellera visible era la rubia, ondulada y en movimiento, que se articulaba con estrategias locales para fijar a la rubiedad como modelo hegemónico.

En un artículo anterior (Aguilera \& Saa, 2016), sostenemos que la rubiedad promovida en las imágenes de las revistas juveniles de los años 30 estuvo relacionada con una matriz discursiva de orden colonial, promovida a través de estos recursos, naturalizando y masificando esta narrativa a través de las revistas ilustradas. En las imágenes, aún en blanco y negro, la rubiedad aparecía como un elemento de distinción y aspiración para la población.

La cabellera rubia continuó a lo largo del siglo reproduciéndose como un signo de distinción frente a otros cabellos, discurso impulsado principalmente por el cine al menos hasta la incorporación de la televisión. En el año 1965, a través de la figura de James Dean y su película Rebelde sin causa, se construiría la imagen del joven de la época: incomprendido, rebelde, semi independiente y con una estética particular que tendría como elemento central la cabellera. El peinado llamativo de este joven rubio, así como su preocupación por él ${ }^{4}$, invoca una estética corporal rupturista a la vez que intenta ser el modelo deseable y tendencia. Esta imagen finalmente marcará una época, y con ello se transformará en hegemónica como imagen del joven de los 60 .

La construcción de este personaje nos invita a reflexionar en torno al viaje de este signo corporal. ¿Cómo durante una buena parte del siglo XX se mantiene estable? Su llegada a las realidades latinoamericanas, y específicamente a Chile, continuó hasta la década del 70 , siendo esta cabellera la que se reproducía en las imágenes de jóvenes de ambos sexos de forma masiva y normalizada. Y es que, en la década anterior, otro ícono-no tan juvenil, sino categorizada como femenino principalmente-, había continuado dando estabilidad a esta cabellera: Marilyn Monroe. Con ella, la rubiedad se vinculará al deseo llevándola a un nivel mucho más atrevido que en décadas anteriores y relacionando esta estética a marcas de ropa y perfumes, por ejemplo.

Otra empresa aparece así en el imaginario y hará su instalación a nivel local: la industria de la moda internacional y su sistema de estrellas, y que llega a Chile principalmente a través de los relatos de las revistas ilustradas que tendrán como central al ocio juvenil. Revistas como Ritmo (1965) o Rincón Juvenil (1964), íconos de los magazines juveniles

\footnotetext{
"Abundan las escenas donde Dean se peina con un peine su "jopo", teniendo este accesorio como indispensable en las nuevas estéticas varoniles, así como en la importancia que se le da al peluquero, dedicando una escena completa a ello. Todas estas nuevas prácticas de arreglo corporal, con énfasis en el cabello, dejan de estar en el terreno del cuidado femenino únicamente, y Dean inaugura así un cuidado más inscrito en el bienestar moderno y masculino.
} 
del siglo XX nacional, seleccionaban reportajes con personajes como "Twiggy", relatando las maravillas de su cabellera -más no ondulada ni en movimiento-, y ampliando geopolíticamente la producción de discursos acerca de la superioridad de esta estética por sobre otras: ya no sólo sería Estados Unidos, sino una Europa a la vanguardia en última moda, la que seguirá insistiendo en el signo de la rubiedad como modelo corporal deseable para las juventudes.

En los años posteriores, la rubiedad se incorporarían a la televisión como otro vehículo más de esta narrativa, sedimentando modas, estilos y estéticas que se correlacionaban a imágenes de chilenas que deseaban para sí esta imagen corporal, y a las que se les enseñaba a partir de productos y prácticas específicas el cuidado de una cabellera rubia imaginada.

\subsection{Panel 3: Cabellera larga, lucha y movimiento}

¿Qué tienen en común el grabado de un joven estudiante de 1937 en una revista estudiantil, con la icónica fotografía de Alberto Díaz (Korda) tomada al Che Guevara, y una foto de Camila Vallejos en las movilizaciones estudiantiles del 2011 en Chile? ¿Cómo se conectan estas imágenes, y qué rol cumple el cabello en ello? Este tercer panel (imagen 4) nos ha permitido traer un conjunto de imágenes para analizar los modos en que la cabellera larga se ha vinculado al cuerpo joven y su lucha en sociedad.

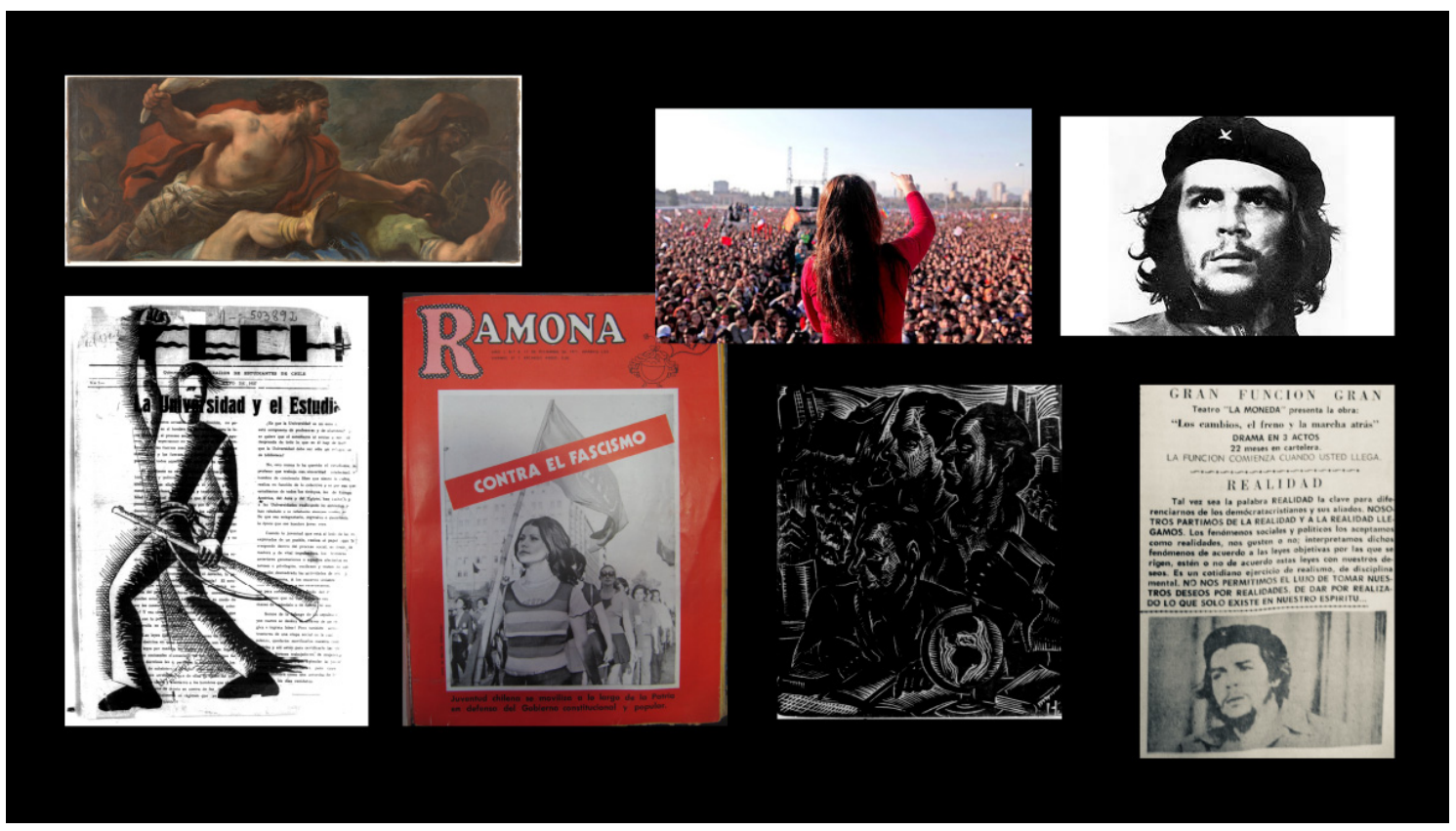

Imagen 4: Panel 3 Cabellera larga, lucha y movimiento 
Corría el año 1960 y el fotógrafo cubano Alberto Díaz, conocido como Korda, capturará en La Habana una de las fotografías más importantes y famosas del siglo XX: el retrato de Che. Dicha imagen denominada "Guerrillero Heroico", traspasará fronteras nacionales y de interés para transformarse en un ícono de la actual cultura pop, y su rostro, barba y cabellos desordenados bajo una boina, se convirtieron a partir de los años 60 en adelante en un objeto de colección y souvenir popular. Dicha fotografía, en términos de cultura visual, fijaría y volvería hegemónica una visualidad en torno al hombre joven que buscaba transformar la sociedad en el Siglo XX.

El Che -su retrato-, que había participado activamente de la Revolución Cubana (19531959), circuló rápidamente transformándose en una imagen popular y que podemos observar en múltiples medios juveniles chilenos tal como Cuadernos Universitarios de 1967, o Acción Popular de 1966, donde su fotografía es utilizada como portada. Las revistas hacían eco de dicha imagen para ilustrar reportajes para los jóvenes donde se señalaba al Che como un ícono a imitar, o como un peligro para ellos, su futuro y la sociedad. A pesar de lo que el texto pudiese señalar, era siempre el rostro barbudo y los cabellos largos y desordenados aquellos que aparecían en las ilustraciones de los reportajes del Che. Era su imagen, la capturada por Korda, la que prevalecería para representarlo y la lucha de la izquierda armada, aquella que inspiraría o atemorizaría a las juventudes del continente.

Sin embargo, la fotografía de Korda vendría a ser la culminación de una imagen que, como principal elemento de representación corporal, traía el cabello suelto, desordenado y largo como canon y representación de los jóvenes luchando en sociedad. Esta imagen si bien parece inaugurar dicha representación, no sería la primera en su tipo, y existen antecedentes en el plano de la cultura juvenil y sus restricciones con la cabellera, así como en la cultura visual y las imágenes que hemos encontrado para este panel, que permiten evidenciar cómo la cabellera larga invoca movimiento y lucha desde tiempos anteriores a la década del 60.

El control por la cabellera larga masculina se ha dado principalmente en dos espacios para las juventudes: la escuela y el aparato militar. Así, la escuela aparece como el lugar por excelencia para calmar las pasiones y controlar el cuerpo juvenil (Toro, 2008). Algunos historiadores nos muestran las similitudes entre Chile y Argentina en cuanto a la corporalidad en la escuela, constituida como dispositivo de disciplinamiento a través de prácticas y estéticas como el uniforme (Toro, 2012) o el corte "militar" del cabello masculino, y que se incorporarán a la cotidianeidad juvenil:

Young men frequently noted a bifurcation of their school and their out-of-school life, which was expressed, for example, in body styles. The schools acted as a major arena for the battles over the length of boy's hair. In 1971 the authorities of a school in Buenos Aires expelled an eighteen- years old boy because, in their view, he did not wear appropriate clothing and his "hair too long". (...) The long hair 
battles then intersected with other struggles over the disciplinary system. (Manzano, 2015: 127).

Por su parte, Mariana Sirimarco (2011) señala como en las fuerzas armadas la construcción de un sujeto militar ha tenido como principal acción formar un cuerpo diferente al cuerpo civil, y donde la cabellera tiene un importante rol por lo que a los hombres se los obliga a despojarse del cabello (cabezas rapadas al 0 y al 1 ), y a las mujeres, eliminar cualquier movimiento a través del uso de coletas. Este ejercicio busca, como señala la autora, eliminar todo vestigio de "civilidad" en estos cuerpos, para así entrar al cuerpo armado y alejarse con ello de la lucha por la sociedad desde un sentido comunitario.

Estas dos instituciones que operan sobre diversos cuerpos juveniles, y que durante el siglo XX tuvieron gran desarrollo y masividad en Latinoamérica, intentaron restringir y fijar el cabello de los jóvenes. Pareciera que determinados cabellos en movimientos son la metáfora del cuerpo joven indisciplinado, aquel que busca generar cambios uniéndose sin mediaciones institucionales a la sociedad. Radica allí el miedo y necesidad de control adulto. Sin embargo, esta estética y la disputa por ella puede rastrearse desde tiempos muy remotos, y siempre ha sido parte de las discusiones en sociedad y sobre la lucha o la guerra.

En la representación mítica, por ejemplo, serán los cuerpos espartanos un modelo cultural donde la cabellera larga tuvo un rol significativo en tanto imagen cultural. Como indica Rivera (2012), esta era un símbolo de masculinidad, que más allá de ser un canon estético masculino universal, era portado por los hombres como simbolización de victoria en la guerra, y también un rito de paso de la edad juvenil a la edad adulta. Esta imagen cultural se representó en la mitología, así como el arte a través de esculturas. Otra imagen mitológica que tiene como protagonista a la cabellera larga de la lucha, es la referente al mito de Sansón, y que está presente con sus cabellos al viento y desordenados, ganando sus peleas, como lo vemos en la pintura barroca de Luca Giordano (ver en panel 3 imagen superior derecha).

Podemos señalar que las cabelleras al viento, largas y desordenadas, en tanto imágenes culturales y visuales se vuelven un ícono de cómo estos jóvenes pueden ganar al rebelarse y luchar por lo que consideran justo. Estas cabelleras se transforman en huellas visuales sobre cómo se configura en el imaginario al sujeto -masculino y jovenluchando en y por la sociedad. Es así como la imagen del grabado de un joven universitario en la revista de la FECH de 1937 (ver en panel 3, imagen inferior izquierda) es rupturista en cuanto a su tiempo y la forma estética de la juventud de la época a la que evoca. Sin embargo, es consistente con esa huella visual y cultural en que el cuerpo ha sido ubicado y confeccionado para la lucha, y donde el cabello en tanto rebeldía y poco control, es la analogía de lo que ese cuerpo es capaz de hacer. 
Como hemos observado, estas representaciones han sido principalmente vinculadas al cuerpo masculino. Lo femenino ha estado presente en menor medida, aunque lo vemos en la representación del famoso cuadro de Delacroix: La libertad guiando al pueblo, donde una mujer joven con su pelo desordenado lidera la lucha. En las revistas ilustradas pudimos encontrar la imagen de portada de la revista comunista Ramona (1972), donde aparece una mujer liderando una manifestación. Esta memoria visual aparecerá casi cuarenta años después, con una imagen de una protesta multitudinaria en Santiago de Chile en el periódico El Mercurio (11 agosto 2011), donde se retratará otro cabello de una mujer comunista, Camila Vallejos, una de las líderes del movimiento estudiantil. De esta forma, dichas imágenes nos están mostrando la recurrencia de este fragmento corporal que, al vincularse con la calle, con la masividad y la protesta, se desordena, se mueve, no se puede controlar, y está en el plano de las indisciplinas del cuerpo. Es también una memoria que recorre el cuerpo joven y sus representaciones visuales ya sean masculinas o femeninas, y que nos comunica el sentido por lo que se está luchando.

\subsection{Panel 4: Cabellos largos y desordenados}

Si bien los cabellos largos que observamos en el panel anterior estuvieron vinculados a una memoria de lucha y a la construcción de la imagen del joven revolucionario(a), otro tipo de cabellera larga y en movimiento vendría a desordenar y habitar el cuerpo joven y se vinculará principalmente a los espacios de ocio como veremos en este cuarto y último panel (ver imagen cinco).

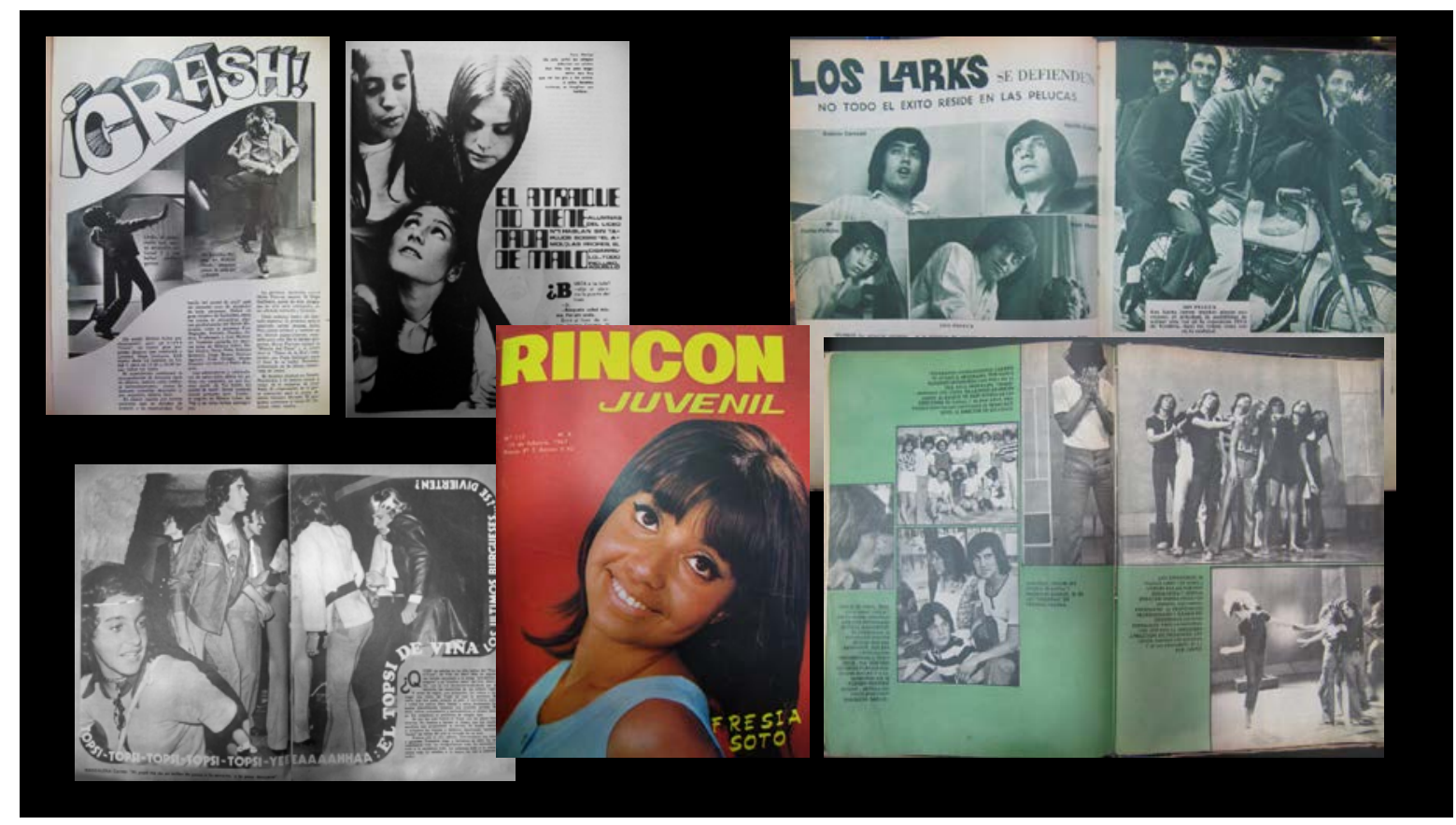

Imagen 5. Panel 4 Cabellos largos y desordenados 
Este panel se construye a través de imágenes exclusivamente de las décadas del 60 y 70 , donde podremos observar cómo se han ido perfeccionando una serie de productos especializados para la juventud, y donde existe cierta homogeneidad en el tipo de estética que se presenta en las revistas.

Entre estas cabelleras encontramos las hippies, largas y desordenadas -y con algún accesorio de adorno-, que a nivel global se expandieron llegando a Chile y vinculándose principalmente con jóvenes de clases altas y acomodadas. En algunos casos tomaron sus estéticas, divirtiéndose en las discotecas de las costas chilenas a principios de los 70 , como se observa del lado izquierdo de nuestro último panel. Estos jóvenes usaban cabelleras largas siguiendo un estilo que al menos en el caso chileno no ingresó de forma contestaría, sino que estaría en el plano de las estéticas juveniles aceptables pues no contenían politización. Otras eran las características de los jóvenes que representaban el peligro para la sociedad, desde los pobres hasta los comunistas e indígenas aparecían en el imaginario como los reales peligros y en imágenes con una corporalidad diferente a las que observamos aquí.

Este estilo del cabello masculino, largo y "chascón", que caracterizaba a una amplia gama de jóvenes no puramente hippies era visto desde el discurso adultocéntrico como informal y hasta ridículo, desactivado políticamente, algo "propio de los jóvenes" como se lee en distintos reportajes y notas de la época:

Moda inspirada en los perros: La moda de las melenas largas en los varones ha interesado a los científicos, sociólogos y psicólogos del mundo entero. Ahora un fotógrafo inglés ha publicado su teoría sobre el origen de este hábito. Según él, los muchachos ingleses se inspiraron en los perros para crear sus peinados. Con el fin de demostrar lo verídico de su descubrimiento, presentó esta foto, con la simpática cara de un perrito que no tiene nada de "colérico" y el rostro de un joven. Al día siguiente el dueño del can lo llevó a la peluquería. Al muchacho no lo ha podido convencer ni la policía de que siga el ejemplo. (Revista Amiga, 9 de enero 1967, pág. 9, Biblioteca Nacional de Chile, DIBAM).

Este tipo de reportajes nos revela otro tipo entrada en la regulación del cabello, y que aparece de forma mucho más sutil y tensionada. Se trata en esta época de una regulación adulta más suave, con un discurso mucho más dócil, que interpela al sentido del humor y que de cierta forma reconoce que el mercado tiene una centralidad en las decisiones juveniles y es más importante que otros discursos reguladores y normativos.

Esta tensión se da principalmente por las modas provenientes a nivel global del mercado juvenil, impulsado por la televisión y la música. Dispositivos se articularán para configurar imágenes culturales sobre este grupo. De esta forma, si bien el pelo largo masculino es ridiculizado, se tensiona con las exitosas modas globales representadas por The Beatles, The Rolling Stones-, y que en el correlato local expresa el grupo musical Los 
Larks que se "defienden porque no todo el éxito reside en sus pelucas" (ver en panel 4 imagen superior derecha). Es una época donde a nivel comunicacional los ídolos provenientes de la música se transforman en referentes de lo juvenil, y donde observamos que esta especificidad industrial aportó una forma concreta a fines de los 60 , formas para ponerse en escena, donde la cabellera larga sería un sello característico para el éxito juvenil.

En el caso femenino, el cabello largo de la década de los 60 y 70 también va de la mano con una reivindicación de éste para encarnar los nuevos tiempos. La mujer de cabello corto y visión moderna ya no está en el imaginario y maneras de representar a la juventud de esta época, y en su lugar estarán las cabelleras largas y desordenadas, lacias y tapando las caras, a través de crónicas a Joan Baez y a las jóvenes que caminan por las calles de Santiago de Chile. Estas jóvenes que muestran como bailan en discotecas, o mueven sus cabellos en los programas de televisión, evidencian que el largo vuelve a ser parte central de lo que caracteriza la femineidad juvenil. Vemos que, para esta época, hay también una reivindicación del cabello oscuro, de las portadas con ídolos locales que muestra y ondean sus peinados sueltos, disputando así a la rubiedad como único modelo -o mejor modelo- para encarnar los atributos juveniles.

\section{Conclusión}

En tanto indicio, el cabello nos ha guiado para comprender las múltiples formas en que los cuerpos juveniles se configuraron en Chile. Las diversas imágenes que revisamos permiten observar a la luz del tiempo, el papel protagónico que los medios de comunicación juveniles tuvieron para presentar, reproducir, movilizar y construir imágenes culturales en torno a ciertos temas, espacios, género y clases de jóvenes. Pudimos así observar una serie de discursos cambiantes sobre lo normal y correcto, y que, a través de textos e imágenes visuales, hicieron de las revistas juveniles un espacio activo en la construcción de narrativas regulatorias para la juventud, y que cumplieron una función de carácter pedagógico para este grupo. En otras palabras, las revistas -y sus imágenes-, fueron un dispositivo central en la configuración y promoción de ideas sobre la juventud a lo largo del Siglo XX.

La metodología utilizada -imágenes, paneles y montaje-, es un ejercicio que nos invita a observar la memoria que contienen las imágenes, comprender las formas en cómo se referencian y citan unas a otras, así como apreciar los efectos que esta memoria visual produce en el plano de las imágenes culturales. Sostenemos que observar imágenes nos permite acceder no sólo a la descripción de estilos y modas de determinados tiempos, sino que con el montaje de cada panel fundamentamos ese estatuto específico del documento visual, no anclado en los modos de representación fijos que da la textualidad 
sino como un documento que puede ser (re)contextualizado y descrito mediante imágenes y sin presuponer una continuidad lineal.

No hemos realizado a lo largo de este análisis una historia de la cabellera juvenil moderna en el Siglo XX, sino un recorrido por ciertos estilos y modas en que el cabello se utilizó, y con ello, ayudó a configurar determinadas imágenes del cuerpo joven. Los usos de ciertas imágenes también son apropiados por la sociedad -y los medios de comunicación en particular-, y actualizados en sus significados culturales cambiantes y atravesados por múltiples discursos. Así, la cabellera y su puesta en escena configuraron una idea de lo juvenil vinculada a discursos raciales, policiales, educativos, y todos aquellos provenientes de la industria mediática global. Comprender los modos imbricados en que se da esta relación, permite avanzar en una genealogía de lo juvenil, así como comprender la propia arquitectura de esta corporalidad juvenil en su relación con la propia modernidad.

\section{Referencias bibliográficas}

Aguilera, O. (2014): "La idea de juventud en Chile en el Siglo XX. Aproximación genealógica al discurso de las revistas de juventud", Anagramas. Rumbos y sentidos de la comunicación, vol. 12, pp. 141-159.

Aguilera, O. \& Saa, M. (2015): "Dispositivo visual y normalización de lo juvenil en Revista Margarita (1934-1939)”. Revista Cuadernos de la Información, n.38, pp. 201-216.

Barthes, R. (1989): La cámara lúcida. Barcelona: Ediciones Paidós.

Burke, P. (2001): Visto y no visto: El uso de la imagen como documento histórico. Barcelona: Editorial Crítica.

Butler, J (2002): Cuerpos que importan. Sobre los límites materiales y discursivos del sexo. Barcelona, Editorial Paidós.

Feixa, C. (1998): De jóvenes, Bandas y Tribus. Barcelona: Editorial Ariel.

(2004): Culturas juveniles en España (1960-2004). Madrid: Instituto de la Juventud.

Foucault, M. (2008): Nietzsche, La genealogía, La historia. Valencia: Ediciones PreTextos.

González, Y. (2011): “Primeras culturas juveniles en Chile: Pánico, malones, pololeo y matiné." Revista Atenea, n.503, pp. 11-38. 
Hallpike, C.R. (1969): “Social hair". Revista Man, núm. 2, pp. 256-264.

Hershman, P. (1974): “Hair, sex and dirt”. Revista Man, vol. 9, núm. 2, pp. 274-298.

Huberman, D. (2010): "Il. Atlas. Portar el mundo entero de los sufrimientos." Museo Reina Sofia. Disponible en Internet (26-02-2018): http://www.museoreinasofia.es/sites/default/files/publicaciones/textos-endescarga/19GD_es.pdf

König, R. (1972): Sociología de la moda. Barcelona, Colección Beta.

Lamadrid, S. (2014). Ritmo revisitado. Representaciones de género en los 60. Santiago: Ediciones Cuarto Propio.

Leach, E.R. (1958): "Magical hair". The Journal of the Royal Anthropological Institute of Great Britain and Ireland, núm. 2, pp. 147-174.

Loy, A. \& Vidart. D. (2008): Cuerpo vestido, cuerpo desvestido. Antropología de la ropa interior. Uruguay, Ediciones de la Banda Oriental.

Manzano, V. (2015): In The Age of Youth in Argentina: Culture, Politics, and Sexuality from Perón to Videla. E.E.U.U: UNC Press.

Mills, W. (1961): La imaginación sociológica. Mexico: Edición Fondo Cultura Económica.

Nateras, A., Valenzuela, J., Reguillo, R. (2007): Los maras. Identidades juveniles al límite. México, Ediciones Universidad Autónoma Metropolitana.

Ossandón B., Carlos y Eduardo Santa Cruz A: (2001). Entre las alas y el plomo: la gestación de la prensa moderna en Chile. Santiago: Editorial Arcis-LOM.

Pérez, J. \& Urteaga, M. (2004): Historias de los jóvenes en México: su presencia en el siglo XX. México, D.F: Instituto Mexicano de la Juventud Archivo General de la Nación.

Purcell, F. (2012): iDe Película! Hollywood y su impacto en Chile 1910-1950. Santiago: Prisa Ediciones.

Reguillo, R. (2012): Culturas juveniles. Formas políticas del desencanto. Argentina, Siglo XXI Editores.

Rinke, S. (2002): Cultura de masas, reforma y nacionalismo en Chile 1910-1931. 1st ed. Santiago: DIBAM Ediciones

Warburg, A. (2010): Atlas Mnemosyne. Madrid: Ediciones Akal. 